\title{
Self-confidence of Nurses Philosophy: A Concept Analysis
}

\author{
Made Suandika ${ }^{1 *}$, Woung-Ru Tang ${ }^{2}$, Mariah Ulfah ${ }^{1}$, Etika Dewi Cahyaningrum ${ }^{1}$ \\ ${ }^{1}$ School of Nursing, Faculty of Health Science, Harapan Bangsa University, Central Java, Indonesia; ${ }^{2}$ School of Nursing, \\ College of Medicine, Chang Gung University, Tao-Yuan, Taiwan
}

\begin{abstract}
\end{abstract}
Edited by: Sasho Stoleski Citation: Suandika M, Tang WR, Ulfah M, Cahyaningrum ED. Self-confidence of Nurses Philosophy: A Concept Analysis. Open Access Maced J Med Sci. 2021 Apr 14;
(T4):206-211. https://doi.org/10.3889/oamjms.2021.5788 Keywords: Philosophy; Nursing; Self-confidence: *Correspondence: Made Suandika, School of Nursing. Faculty of Health Science, Harapan Bangsa University, Central Java, Indonesia E-mail: madesuandika@uhb.ac.i Received: 20-Jan-2021 Revised: $31-$ Mar-2021 Copyright: $\odot 2021$ Made Suandika, Woung-Ru Tang, Mariah Ulfah, Etika Dewi Cahyaningrum
Funding: This research did not receive any financial support ors have declared that no competing interest exist Open Access: This is an open-access article distributed under the terms of the Creative Commons AttributionNonCommercial 4.0 International License (CC BY-NC 4.0)

\section{Introduction}

Nursing is born together with the human. Hence, it cannot be denied that everyone needs nursing care in his life. At first, the nurse jobs was considered as a career, where implantation was done traditionally by groups, communities, or social institutions [1]. The development of nursing as we know it today is greatly influenced by the development of the structure and progress of human civilization [2]. The statistical data in nurses self-confidence in the world revealed that $90.5 \%$ decreased confidence of a nurse in providing and managing patient care. Changes in nurse confidence lead to slow but steady changes in the level of confidence in the clinical setting and patient care [1], [3]. The beliefs in animism, the spread of major religions, the world and the socioeconomic conditions of society, the occurrence of wars, revival, and reformation movements also color the development of nursing [2], [3].

Nursing as an integral part of health services also determines the quality of health services. Nursing force as a whole dominates existing health personnel, in which nursing uniquely to the form of health services as a relative, sustainable, coordinative, and advocating unit [2], [4]. Philosophy in nursing is arguments, which are written expressing the beliefs, values, and morals of both preventive and curative nurses in serving patients in the values of the nursing profession. From those aspects, the nurses can know the experience of others and take lessons from that experience for us to use now and in the future.

The concept is an idea where there is an abstract impression that can be arranged into real symbols, while the concept of nursing is the idea of constructing a conceptual framework or nursing model [5]. Nurses always support and help colleagues, nursing students, to maintain a positive team atmosphere so that they can collaborate to maximize patient health recovery [6].

Self-confidence as a nurse has a positive impact on bright values to be able to maximize the image of the nursing profession through morale in improving services to clients and being responsive to involvement in serving society, politics, and professional organizations [7]. Through this discussion, nurses can significantly improve nursing service standards both locally and internationally [8]. In carrying out an understanding of the personal philosophy of nursing, it benefits others [2], [3], [9].

The implication of the nursing philosophy is the basic framework that nurses must have as a guide to 
thinking, make decisions, and act/behave in implementing nursing practice to clients, but in fact, some nurses are still lacking in confidence [10]. The inability to show selfconfidence is often based on the result of nurses who have less cognitive abilities, limited skills, and experiences that are not supported by the desire to develop themselves because they are stuck with routines at work [11].

This paper points out the value as selfconfidence as an important philosophy required regarding patient care. In this study, the eight-step analysis, the concept introduced by Walker and Avant [11] is used to be the framework of the analysis process with the nursing theory model. It limits the nursing services and related cases presented together with several perspectives, antecedents, consequences, and empirical references that are considered as important components that nurses must have in general.

\section{Nursing experts on the philosophy in nursing}

The values underlying the concept of nursing include the concept of man, health, environment, and nursing [4]. Nursing philosophy is a combination of assumptions, beliefs, and values about knowledge and truth as outlined in a metaparadigm. Some researchers had the expertise in nursing theory and becoming outstanding nursing leaders discovered and developed grand and middle range theory in nursing science which are presented in the following:

\section{Jean Watson (caring)}

Caring is a science that embodies humanity, the orientation of human knowledge to the process of care for human beings, events, and experiences [8]. The science of caring knowledge includes art and humankind as well as science. Caring behavior includes listening attentively, comforting, showing honesty, patience, and responsibility, and providing information so that the patients can make decisions [5], [8], [9], [10].

\section{Betty Neuman}

It uses the whole human approach by incorporating holistic concepts, open system approaches, and the concept of stressors. The client system consists of five reacting variables: Physiology is body structure and function psychology is mental processes and relationships. Sociocultural aspect is a combination of social and cultural functions; meanwhile, the development is the development process of human. As an addition, the spiritual means the spiritual belief [4].

\section{Calista Roy}

It uses eight philosophies. Four are based on the philosophy of the principle of humanism and the other four are based on the principle of the philosophy of reactivity. The philosophy of humanism recognizes the man and the subjective side of the man and his experience as a center of curiosity and respect. He argues that an individual interacts in the ability to think creatively, acts for a particular purpose rather than simply fulfilling the law of action-reactions, possess intrinsic colorism, strives to maintain the integrity, and understanding the need to have relationships with others [8], [11]. Reactivity, meaning the truth, is meant to express Roy's belief that something is true. It defines reactivity as the natural principle of man which affirms the general purpose of human existence. The four philosophies based on the principle of reactivity are described as follows. Individuals are viewed in the context of the purpose of human existence, the composite of some of the goals of human civilization, activity and creativity for the common good, and the values and meaning of life [5].

\section{Florence Nightingale (modern nursing)}

Florence Nightingale is a modern-day pioneer in the development of nursing that is strongly influenced by his philosophical view of client interaction and his environment [4]. Other researchers view disease as a process of replacement or repair of the reparative process [12]. The manipulation of external escalating environment can help the patients.

According to some perspectives above, nursing philosophy is a guideline and a grip in our attitude and behavior in implementing nursing practice toward the patients in the healthy sick range with the underlying the concept of nursing include human, health, environment, and nursing.

\section{Nursing metaparadigms of the art of nursing science}

The philosophy of nursing experts has previously shown the values that underlie the concept of nursing in the form of the human concept, the concept of health, the concept of the environment, the concept of nursing [4]. Nursing philosophy is a description of the assumptions, values, and basic concepts, knowledge, and truth about the nature of a person who is expressed in the metaparadigm. Few researchers are experts in nursing theory and they are exceptional nursing leaders who discover and develop grand and middle range theory in nursing. According to some of the above perspectives, in our perspective, the philosophy of nursing is a guideline and guide in our attitudes and behavior in carrying out nursing practice toward clients in the healthy sick range with the underlying concepts of nursing include human, health, environment, and nursing.

The paradigm in nursing is the philosophical foundation that supports our research approach. Nursing philosophy and scientific advancement 
are based on the conceptual values of the nursing metaparadigm [4], [5], [7]. The identified nursing metaparadigms include the main concepts of people, health, environment, and nursing [13]. The concept of nursing metaparadigm is an integral part of the development of nursing knowledge as part of the nursing science, which refers to the values that are guaranteed be an impact on nurses and patients to support human health [4].

Self-confidence is an important thing that nurses must have confident when taking actions that require strong encouragement for nurses spontaneously, but from all of the above theories, the concept of self-confidence has not emerged literally, even though it is conceptually. Nurses' confidence is very important in nursing care so that comprehensive and sustainable services can be carried out properly and achieve patient satisfaction.

\section{Implications of Self-Confidence Analysis Research is the Development of Metaparadigm in Nursing (Conceptual Framework)}

Several nursing philosophies and theories examine the importance of providing patient care to achieve recovery [1], [2], [14], [15]. The philosophy of nursing has the value of objectivity, measurement, quality, and validity as the foundation of the main view which is equipped with a nursing model that is task oriented and which still greatly influences the theory of care and nursing practice. This paper shows the philosophy of personal nursing, namely, society, environmental health, nursing care passengers, and the confidence of nurses who are adopted based on nursing metaparadigms in general, namely, patient, nurse, health, and the environment [12], [13].

The conceptual framework to support my philosophy also comes from a description of previous experiences of nurses. This conceptual framework diagram emerged based on my perceptions and is supported by many other studies that can be derived from this conceptual framework for my professional career [14], [15], [16]. However, due to time and space limitations, only our initial ideas are presented in this paper. Many studies can be derived from this conceptual framework. Two investigative studies and research questions were posed as follows: The relationship between patients, a healthy environment can mutually influence the health status of patients, the relationship between the community and health passengers is the patient [12], [13], [15]. Besides, there is also a relationship between nurses' self-confidence and society, environmental health, and also the patient itself.
The synthesis and development of the basic metaparadigm concepts in nursing emphasize the confidence of nurses as the most important part of today's nursing philosophy, besides that, we also emphasize that society, healthy of environment, and the passenger of nursing care relationships support therapeutic relationships with patients, families, and communities (Figure 1) [12], [13], [16]. All of them are biopsychosocial interactions and each component is interrelated and interconnected. The value of nursing philosophy is expected to be new for the nursing profession in synergy to be able to develop according to current patient needs [17], [18]. These differences are based on inherent characteristics and the process of psychosocial development. All of these contribute to a person's unique cognitive structure for better understanding self-confident in a deep belief in oneself [19]. The first is related to self-love, knowledge, and the ability to behave positively. The latter is related to the way of speaking and holding back the emotions of the nurse who provides care to the patient. This feature allows self-confidence to be predicted as self-evaluation [13].

However, the development of one's selfconfidence can stem from repeated experiences that lead to a reinforcement of the perception of success or failure [14]. Self-confidence is also multifactorial, because it is related to the interaction of cognitive and behavioral abilities, and is influenced by the environment. An positive environment in which other members of the professional multidisciplinary team will encourage nurses to have a philosophy in nursing synergistic and appropriate, have a positive impact on strengthening the confidence of nurses in everyday life [20].

Nurse confidence is a philosophical element that has various points of view in nursing theory and becomes the strength of nurses as stated in the basic science of nursing including compassion and health, honesty, and character [15]. Nursing metaparadigm guides a nurse's perspective to be stronger and more confident for current and future nursing care. This paper discusses the nursing

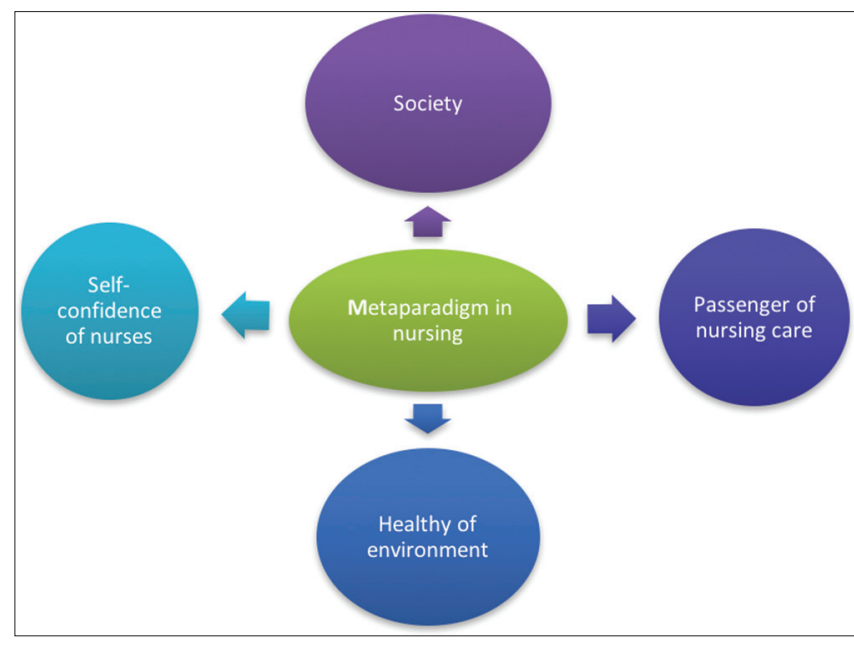

Figure 1: The concept analysis metaparadigm in nursing development of conceptual framework [8], [14], [21], [22] 
philosophy dealing with nursing philosophy deals with four domains: Society, healthy of environment, the passenger of nursing care, and self-confidence of nurses. The four domains are defined as follows:

\section{Society}

Our definition is the simplest means that society is a group of people who have the same interests and concerns if they are exposed to the same or different populations [23]. Understanding society is a social relationship that affects each other. With society there will be social interaction, humans can relate to each other so that it is possible to live together and show individual reactions and patterns in responding to others. Based on this theory, people's lives are influenced by existing social pressures. Thus, the behavior is a response to the social environment, especially regarding community groups that can develop into certain circumstances [4], [16], [19] such as the service at the hospitalas an example, in the surgical ward service has mentions that in this surgical ward, the people can be considered as a society where the nurses in the room will be united by the mutual benefit to provide a level of care to patients who are instructed about their patient care.

\section{Healthy Environment}

The simple meaning of healthy of the environment is an area for people to survive we can manage at the environment to become healthy, for example, in the surgical ward, all people who in this place should follow a standard of procedure of sterile area of this area, we do the same intervention for all people who is in this area such as wearing a mask and use the cloth surgical. As a sociocultural being, the human is shaped by the environment where they live. The internal factors of the environment are physiological, psychological, and ethical factors. Meanwhile, the external factors are cultural, political, social, economic, professional, and global factors [8], [21].

The healthy environment puts the external environment as the internal environment [19]. The external environment consists of biological, physical, social, and cultural variables. The internal environment consists of personal characteristics, physical growth and development, immune system regulation such as neurological system, changes in body repair, and human behavior. Such an environment affects the health of individuals and groups as well as the health service delivery systems, access to care, and health implementation.

Besides, the community must be responsible for providing a conducive environment to maximize the potential of individual and community members, to avoid permanent non-conformities that play a role in the health offering, and to carry out the duties and functions of its members. After all, they provide in health environment because optimal health disagrees; health and disease on a continuum parallel even to people with chronic or infirm illnesses who may increase optimal health through adaptation [4]. We believe that all humans, from infants to old ages, have a great deal with health and disease, both environmental and genetic. The role of nursing for appreciation, adaptation support, or appropriate compilation interventions does not exist in individuals or groups. Because health is a human characteristic, it is believed that high-quality health care is a human right.

The environment in this situation can be described as the physical environment such as the place where people live, the structure of the house, or every area that the people encounter. It is assumed that the environment also includes mental in the passengers in the environment as well as the awareness of the community. This includes awareness, the mind of the state of the self, and the recent destruction of the environment.

Health is a thing that must be taken into account. The statement is based on information of health stated as follows: "Health is a process of accumulation that can be used as something that interrupts or undermines the health process itself." All interactions among the community, the environment, and the patients or treatment passengers are dynamic and synergetic.

\section{The passenger of nursing care}

The passenger of care is not only limited to patients, families, friends, men or women, and other members of the care but the recipient of care should also cover the nurse staff themselves. One of the examples of the care is by washing hands before and after giving treatment. Do nurses require care for themselves? The answer is "yes." Everyone who comes into contact with the nursing process is also can get both positive and negative impacts. It is believed that the dignity of every human being must be nourished and nurtured. People must embrace the diversity that people have by accepting and respecting every person. Researchers assume that humans are unique individuals, change behavior, and have values related to the environment, social ethics, culture, body shape, experience, religion, and its applications [9]. Humans are in relationships with each other, including family, community, and population as well.

\section{The self-confidence of the nurses}

In collaborating with others, nurses must be able to take smart and confident actions so that nurses can make changes for the other people by considering 
what is good or bad for their health [11], [13], [16], [24], Thus, before we can make others better, it would be wise that nurses have already had good health and high self-confidence at first. Furthermore, nurses must develop caring and smart steps in collaborating with other professionals in nursing care and adjust to the development of the current era of technology that supports healing [24], [25].

I remember the experience of my life when I accompanied my aunt to provide care for the patient and helped a woman delivering her baby. At the time, I thought I dreamed to be a nurse. I remember that I was longing to grow when I could wear a white and clean uniform. However, for years, my definition of being a nurse was changed. I am a person who is not in uniform. I later found out that the nurse does not have to wear white and cannot wear clothes in different colors (Made Suandika experiences).

Actually, in doing nursing service, nursed do not only pay attention to the color of uniform the nurses wear. However, there is a more crucial thing that is to increase the nurses' confidence in giving treatment to the patients. Confidence in our self will grow well if we have made a strong foundation on improving our knowledge through open self-awareness nurses to always want to learn so that they can do the appropriate nursing care and finally if there is collaborative nursing, the nurses can also do well and in an organized manner.

Self-confidence is often referred to as the science of assuming free values in nurses and having great positivist values considering traditional metaparadigms and ethical considerations that are concerned the emotions and not only related to cognitive aspect [16], [17], [20], [26]. On this basis, the development of nursing in the theoretical development needed to be based on an approved scientific view makes progress faster and its development can be seen as an example for other academic disciplines such as medicine and science. Nursing philosophy realizes the important role of nurses in noble care. The development of nursing philosophy is a therapeutic relationship among nurses and patients which is the basis of nursing practice to get an improved QoL of patients after getting treatment [17], [27].

Providing care with confidence done by nurses existing as a community is to protect its members through roles, responsibilities, and support rooms approved by law [11], [16]. Nursing is a scientific discipline that is centered on helping people to support, motivate, and improve their health and abilities to prevent and defeat the disease as well as to alleviate the suffering [25]. The nurse has the diagnosis and implementation of nursing interventions for the patient's health condition, protection in individual and group care, in the realm of nursing practice [23].

The concern for a comprehensive agreement based on consideration and human love, respect for dignity, and the self-confidence that exists in humans [11], [13], [16], [27]. These beliefs about caring for others, based on a systematic process of consent, planning, implementation, and evaluation, are supported to optimize adaptability in humans [24], [25]. Nurses have a moral responsibility to share well-being and an obligation for social and equal access to culturally sensitive and high-quality care for all human beings [11], [13], [16], [27]. Nurses are also responsible for helping vulnerable people to recover health, both locally and internationally [26].

In the discussion of self-confidence, there are some literature presents some findings focusing only a little on the concepts of the nurses' beliefs and their experiences about the factors that contribute in building trust with the patients. The first is the normal condition associated with the nurse in the relationship [16], [27], [17], [18]. It is an external factor that is significant to engage in work practices. The literature does not mention what is important for them to find them. Therefore, literature studies legitimize implementations that address the understanding of the concepts of belief and reflection in the relationship with their patients.

The meaning of this philosophy shows that nursing can be provided wherever and by whoever can show love and care. The definition changes little compilation of speech professional nurse. These nurses must provide care by the specified library by the American Nurses Society and the rules of self-confidence.

\section{Conclusion}

Every nurse must understand the philosophy of nursing as a guide in acting and behaving in nursing practice. On the other hand, nurses must also understand the aspects in balance including how to make society and human to be healthy, to decrease the sickness, to improve the health of the environment, to increase selfconfidence, and to balance the health of nurses.

\section{References}

1. Wojnar D, Swanson KM, Aldolfsson A. Confronting the inevitable: A conceptual model of miscarriage for use in clinical practice and research. Death Studies. 2011;35(6):536-58. https://doi.org /10.1080/07481187.2010.536886

PMid:24501829

2. Angeles-Llerenas A, del Río AA, SalazarMartínez E, Kraus-Weissman A, Zamora-Muñoz S, HernándezAvila M, et al. Perceptions of nurses with regard to doctor-patient communication. Br J Nurs. 2003;12(22):1312-21. https://doi. org/10.12968/bjon.2003.12.22.11894 


\section{PMid: 14688652}

3. Austgard K. The aesthetic experience of nursing. Nursing Philosoph. 2006;7(1):11-9.

PMid:16412198

4. Stewart MW. Philosophy of Nursing. Burlington, Massachusetts: Jones and Bartlet Learning; 2008. p. 101

5. Chinn PL, Kramer MK. Integrated Theory and Knowledge Development in Nursing. St Louis, MO: Mosby, Inc.; 2011.

6. Panteka KK, Pizirtzidou E. The concept of self-esteem in nursing education and its impact on professional behaviour. Int J Caring Sci. 2014;7(1):6.

7. Mazzotta CP. Biomedical approaches to care and their influence on point of care nurses: A scoping review. J Nurs Educ Pract. 2016;6:93-101.

8. Warelow PJ. Changing philosophies: A paradigmatic nursing shift from Nightingale. Aust J Adv Nurs. 2015;31(1):1-10

9. Mason J, Wesorick B. Successful transformation of a nursing culture. Nurse Leader. 2011;9(2):31-6. https://doi.org/10.1016/j. $\mathrm{mnl} .2011 .01 .001$

10. Kukulu KK, Ozdemir Y, Bezci A, Calik C. Selfconfidence, gender and academic achievement of undergraduate nursing students. J Psychiatric Ment Health Nurs. 2013;20(4):330-5. https://doi. org/10.1111/j.1365-2850.2012.01924.x

PMid:22583626

11. Avant LW. StrategieS for Theory Construction in Nursing. Vol. 6. London, United Kingdom: Pearson; 2005.

12. Wade G, Kasper N. Nursing students' perceptions of instructor caring: An instrument based on Watson's theory of transpersonal caring. J Nurs Educ. 2006;45(5):162-8. https:// doi.org/10.3928/01484834-20060501-05

PMid:16722498

13. Andershed B, Olsson, K. Review of research related to Kristen Swanson's middle-range theory of caring. Scand J Caring Sci. 2009;23(3):598-610. https://doi. org/10.1111/j.1471-6712.2008.00647.x

PMid:19552794

14. Huffman C, Swanson KM, Lynn M. Measuring the meaning of miscarriage: Revision of the impact of miscarriage scale. J Nurs Measur. 2014;22(1):29-45. https://doi. org/10.1891/1061-3749.22.1.29

PMid:24851662

15. Kolcaba K, Tilton C, Drouin C. Comfort theory: A unifying framework to enhance the practice environment. J Nurs Adm. 2006;36(11):538-44. https://doi. org/10.1097/00005110-200611000-00010 PMid:17099440

16. Gold C, Haas S, King I. Conceptual frameworks. Putting the nursing focus into core curricula. Nurse Educ. 2000;25(2):95-8. https://doi.org/10.1097/00006223-200003000-00012 PMid:11052009

17. Espinosa-Rivera BP. Self-confidence and anxiety as intervening factors in clinical decision-making in newly nursing bachelor graduates. Am J Nurs Sci. 2019;8(2):59-67. https://doi. org/10.11648/j.ajns.20190802.14

18. Booth-Laforce C, Scott CS, Heitkemper MM, Cornman BJ Lan MC, Bond EF. Complementary and alternative medicine (CAM) attitudes and competencies of nursing students and faculty: Results of integrating CAM into nursing curriculum. J Prof Nurs. 2010;26(5):293-300. https://doi.org/10.1016/j. profnurs.2010.03.003 PMid:20869029

19. Schorr E. Theoretical framework for determining hospital length of stay (LOS). BMC Proc. 2012;6 Suppl 4:P32. https://doi. org/10.1186/1753-6561-6-s4-p32.

20. Center FR. Mission and values statemen towards a philosophic theory of nursing. Nurs Philos. 2007;5:79-83.

21. Greenwood AC. The lived experience of clinical development unit. J Adv Nurs. 2001;34(3):408-16.

PMid:11328446

22. Dubé $V$, Ducharme F. Nursing reflective practice: An empirical literature review. J Nurs Educ Pract. 2015;5(7):94-9.

23. McDonald MM. Contemplating the fit and utility of nursing theory and nursing scholarship informed by the social sciences and humanities. Adv Nurs Sci. 2013;36(1):10-7. https://doi. org/10.1097/ans.0b013e31828077bc

PMid:23370496

24. White KA. The Development and Validation of a Tool to Measure Self-Confidence and Anxiety in Nursing Students While Making Clinical Decisions. Las Vegas, Nevada: University of Nevada; 2011.

25. Panduragan SL, Abdullah N, Hassan H, Mat S. Level of confidence among nursing students in the clinical setting. Proc Soc Behav Sci. 2011;18:404-7. https://doi.org/10.1016/j. sbspro.2011.05.059

26. Chesser-Smyth PA, Long T. Understanding the influences on self-confidence among first-year undergraduate nursing students in Ireland. J Adv Nurs. 2013;69(1):145-57. https://doi. org/10.1111/j.1365-2648.2012.06001.x PMid:22486537

27. Cody WK, editor. The nursing discipline and the development of nursing knowledge. In: Philosophical and Theoretical Perspectives for Advanced Nursing Practice. Vol. 5. Burlington, MA: Jones and Bartlett Learning; 2013. https://doi. org/10.1177/0894318413477150 